\title{
CFD Study of Huge Oil Depot Fires - Generation of Fire Merging and Fire Whirl in Arrayed Oil Tanks
}

\author{
KOYU SATOH ${ }^{1}$, NAIAN LIU ${ }^{1}$, XIAODONG XIE ${ }^{1}$, KUIBIN ZHOU $^{1}$, HAIXIANG CHEN $^{1}$, JINMO \\ $W^{1}$, JIAO LEI $^{1}$, and JESSE S. LOZANO ${ }^{2}$ \\ ${ }^{1}$ State Key Laboratory of Fire Science \\ University of Science and Technology of China \\ Hefei, Anhui 230026, China \\ ${ }^{2}$ Department of Mechanical Engineering \\ University of California Riverside \\ CA, 92501 USA
}

\begin{abstract}
One of the largest industrial fire disasters may occur in oil tank depots which store large amounts of oil. Many previous studies on the fire safety of oil tank depots have been related to the fire propagation from one single oil tank fire to the adjacent tank via radiation. However, single oil tank fire may cause a fire whirl in windy conditions, entraining much more ambient air and enhancing flame radiation, which may increase the possibility of fire propagation toward the neighboring tanks. In addition, when an oil depot storing a large amount of oil in tanks is subject to destructive earthquakes, merging fires and fire whirls may be generated, leading to disastrous consequences. In this work, the authors examined the fire merging and fire whirl behaviors in multiple huge oil tank fires by CFD simulations using FDS v4. The constant heat release rate model was employed and the effects of tank-to-tank distance, wind speed and heat release rate were examined. It was found that these parameters are important to cause fire merging and fire whirls, and at the same time, the conditions to cause fire merging and fire whirls lie in a limited range. Some relevant correlations were established. The results are expected to be useful for mitigating the disasters due to fire merging and fire whirls.
\end{abstract}

KEYWORDS: CFD, fire merging, fire whirl, flame height, heat release rate, oil depot, oil fire.

\section{NOMENCLATURE LISTING}

$\begin{array}{llll}A & \text { circular burn area of oil tank }\left(\mathrm{m}^{2}\right) & Q_{D}{ }^{*} & \text { non-dimensional heat release rate } \\ c_{p} & \text { specific heat }(\mathrm{J} / \mathrm{kg} \cdot \mathrm{K}) & s & \text { distance from a tank center }(\mathrm{m}) \\ D & \text { diameter of oil tank }(\mathrm{m}) & T & \text { temperature }(\mathrm{K}) \\ g & \text { gravitational constant }\left(\mathrm{m} / \mathrm{s}^{2}\right) & U & \text { wind speed }(\mathrm{m} / \mathrm{s}) \\ h & \text { height of oil tank }(\mathrm{m}) & Z_{f} & \text { flame height }(\mathrm{m}) \\ q & \text { heat release rate per area }\left(\mathrm{kW} / \mathrm{m}^{2}\right) & T_{0} & \text { ambient temperature }(\mathrm{K}) \\ L & \text { tank center-to-center distance }(\mathrm{m}) & t & \text { time }(\mathrm{s}) \\ M & \text { air mass flow rate }\left(\mathrm{m}^{3} / \mathrm{s}\right) & \text { Greek } & \\ Q & \text { total heat release rate }(\mathrm{kW}) & \rho_{0} & \text { ambient air density }\left(\mathrm{kg} / \mathrm{m}^{3}\right)\end{array}$

\section{INTRODUCTION}

One of the largest disasters in industrial fires may exist in oil tank depots which store much amount of oil. The number or scale of oil tank depots is obviously increasing in recent years. Previously the major concern for oil tank fires was on the propagation from an oil tank to its adjacent ones, relevant to radiation heating. However, in any single fire if a fire whirl is induced in some windy conditions, the burning rate may increase due to more supply of entrained ambient air, causing the radiation be enhanced. Therefore, oil tank fire propagation may become a more serious problem when under a swirling condition. In addition, there is a possibility of such disasters especially when the depots are subject to destructive earthquakes [1]. A larger number of accidental fires at oil tank depots have been reported around the world [2-4]. Insight into literature reveals that in 1960s some fundamental merging and the flame-height extension phenomena were studied by Baldwin [5] and Thomas et al. [6]. In recent years, Liu et al. [7-9] have examined the merging phenomena in multiple flames. They used the burn-out time data to characterize the interactions in square arrays, thereby the critical conditions for the merging were quantitatively determined. Also Satoh et 
al. [10-14] have conducted CFD simulations to examine the behaviors of fire merging and its induced fire whirl. Flame height of merged flame in multiple fire sources has been studied by Weng et al. [15], but it is related to wooden city fires, without consideration of fire whirl. There have been also many studies [16-24] on individual oil tank fires or fire spread between adjoining tanks. Nevertheless, there have been few reports concerning fire merging and fire whirl generation in huge oil tank depots, and especially the physical characteristics of such disastrous fire phenomena has not been examined or even fully clarified. In view of these facts, in the previous studies of the authors [25,26], we conducted elementary analyses on the generation of fire merging and fire whirls in multiple huge oil tank fires by using CFD simulations based on the software of FDS v4 developed by NIST, in order to determine the conditions for the occurrence of these phenomena. Particularly, one problem is that large oil fires produce so much soot and thus the real heat release rate, contributing to the merging and swirling flows, remains uncertain. Therefore, this study was based on the constant heat release model by FDS v4, and the conditions to cause fire merging and fire whirls in the multiple oil tank fires were further examined, by varying the wind conditions, tank-to-tank distance and the total heat release rate in various arrays.

\section{CFD SIMULATION METHOD}

\section{Scenario of Oil Depot Fires}

In this study, primarily $(7 \times 7)$ arrayed oil tank fires are investigated, including cases of other array sizes. The scenario simulates huge oil tank depots which store totally several million kiloliters oil in a square area with side length of nearly $1 \mathrm{~km}$. Figure. 1 shows a schematic of an oil tank depot, where the diameter $(D)$ of each oil tank is $80 \mathrm{~m}$ and the height $(h)$ is $20 \mathrm{~m}$. The circular combustion area $(A)$ of an oil tank is $5026 \mathrm{~m}^{2}$, and the uniform tank center-to-center distance $(L)$ between any two adjacent oil tanks is $160 \mathrm{~m}$, and it is also variable. A large fire may occur in single oil tank due to earthquakes or other accidents. Particularly during the huge earthquakes, strong swaying motion may cause sparks during frictions between steel tank and cover or with something, which can ignite multiple tanks simultaneously. The possibility of fire occurrence of this study is: (1) single tank fire propagates to one neighbor after the enhanced heat release rate and increased radiation due to fire whirl toward the spilt oil and finally to multiple fires, or (2) multiple fires occur simultaneously under earthquakes and propagate to their neighbors. In this fire whirl study, a uniform wind at a constant speed $(U)$ is applied along one edge of an oil tank array to provide a shear wind against the fires, with dimensions of $300 \mathrm{~m}$ in height and mostly $300 \mathrm{~m}$ in width (except for single fire and $(17 \times 17)$ array fires), while for the fire merging studies, calm air conditions are employed.

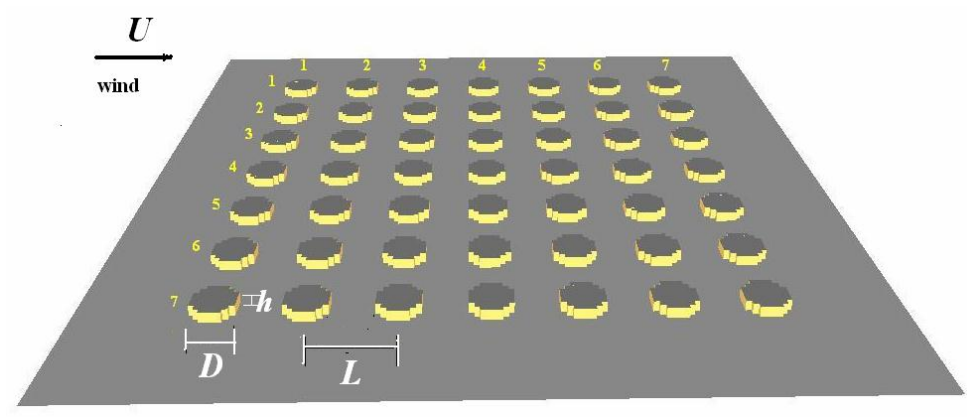

Fig. 1. Schematic of a $(7 \times 7)$ array of oil tanks.

\section{Grid Number, Grid Size and Time Step}

For most $(7 \times 7)$ arrayed oil tank fires, $10 \mathrm{~m} \times 10 \mathrm{~m}$ grid for the two horizontal directions and $10 \mathrm{~m}$ grid for the vertical direction are employed. The number of grids is $150 \times 150$ for horizontal direction and 100 for vertical direction, and thus the domain is made by $1500 \mathrm{~m} \times 1500 \mathrm{~m}$ in horizontal direction and $1000 \mathrm{~m}$ in vertical direction. The grid size for $(5 \times 3)$ and $(5 \times 5)$ array fires is the same as those for $(7 \times 7)$ array fire, but the number of grids is dependent on the array area. For smaller area fires, such as single fire, $(1 \times 2)$, $(2 \times 2)$ and $(3 \times 3)$ array fires, the grid size of $(5 \mathrm{~m} \times 5 \mathrm{~m})$ for two horizontal directions and $5 \mathrm{~m}$ or $10 \mathrm{~m}$ in the vertical direction is employed. Time step of $0.1 \mathrm{~s}$ or $0.2 \mathrm{~s}$ is employed, depending on the total calculation time. The floor is adiabatic and the top boundary and four side boundaries are open. At one 
corner wind is supplied into the domain, as mentioned above. The effects of the Coriolis force, which is important in typhoon simulations, is not considered in this study, since the effect is minor in this study by our preliminary calculation due to the scale ratio. The computation time is roughly $3-4$ days, using $2.7 \mathrm{GHz}$ PC.

\section{COMBUSTION MODEL}

In this study, no particular combustion model is employed, but a constant heat release rate is specified. One reason is that for large oil tank fire, the combustion model in FDS v4 with default values gives far taller flames compared to the empirical values. Therefore, the soot yield, $\mathrm{CO}$ yield and radiation fraction, etc., should be properly specified. However for huge oil tank fires no adequate data to specify are available. This will be mentioned later, relevant to the equation of Zukoski et al. [27]. The second reason is that this study employs single grid of like $10 \mathrm{~m}$ cubes, which may be too large to capture the burning rate and chemical reaction in oil tank fires. The third reason is that this study is related to fire merging and fire whirl, which extremely enhance the burning rate of oil in tank depots, and also cause the soot yield decrease. However, the detailed combustion model for fire merging fire and fire whirl in huge oil tank fires is not yet available. In addition, this study has used FDS v4, instead of FDS v5 [28]. One reason is that the authors have already started this study before 2007. Also we compared with the results between FDS v4 and FDS v5, and found that both gave almost the same results, as long as the constant heat release model was used.

\section{Comparison of Flame Heights between Simulated Results by FDS v4 and Equations by Zukoski et al.}

As a preliminary investigation, a comparison between the simulated results and reduced-scale experimental data by the authors has been made. In the experiments, $n$-heptane as a fuel was put into a circular steel pan, with diameter of $0.05 \mathrm{~m}$ and the height of $0.02 \mathrm{~m}$. After ignition, the flame height for the n-heptane flame was measured by video. As a result, the predicted flame heights by FDS v4, corresponding to the reducedscale experiments are slightly smaller than those in the experiments. In addition, the flame heights obtained by FDS v4 and by the following equations due to Zukoski et al. [27] are compared.

$$
\begin{aligned}
& Q_{D}^{*}=Q /\left(\rho_{0} \cdot C_{p} \cdot T_{0}\left(g \cdot D^{5}\right)^{0.5}\right) \\
& Z_{f} / D=3.3\left(Q_{D}^{*}\right)^{2 / 3}, Q_{D}^{*}<1 \\
& Z_{f} / D=3.3\left(Q_{D}^{*}\right)^{2 / 5}, Q_{D}^{*}>1
\end{aligned}
$$

The flame heights in various cases by FDS v4 are examined as functions of $D$ and the total heat release rate $Q$. The simulated fire profiles for the fuel diameter $D=0.05 \mathrm{~m}$ and $Q=1.96 \mathrm{~kW}\left(q=1000 \mathrm{~kW} / \mathrm{m}^{2}\right)$ are shown in Fig. 2a, although it is uncertain for real flame heat release rate distribution. The average flame height given by FDS v4 is $0.23 \mathrm{~m}$, while Eqs. 1 to 3 result in a flame height of $0.30 \mathrm{~m}$. For $D=0.06 \mathrm{~m}$, FDS $\mathrm{v} 4$ and the above equations respectively give flame heights of $0.26 \mathrm{~m}$ and $0.30 \mathrm{~m}$. The simulated flame heights in the reduced scale model region with $D$ less than $1 \mathrm{~m}$ are slightly lower than those obtained from Eqs. 1 to 3, as shown in Fig. 3. Equations 1 to 3 may be not always certain for larger fires, such as $D=80 \mathrm{~m}$, but the comparison is made, since previous studies [19-21] indicate that the flame height is close to tank diameter for large oil fires and the Eqs. 1 to 3 give not so far values. At $D=80 \mathrm{~m}$ and $q=1500 \mathrm{~kW} / \mathrm{m}^{2}$, the time-averaged flame height given by FDS $\mathrm{v} 4$ is approximately $230 \mathrm{~m}$, as shown in Fig. 2b, while that from Eqs. 1 through 3 is $128 \mathrm{~m}$. This discrepancy can be found in the region of the fuel diameter $D$ larger than $8 \mathrm{~m}$, corresponding to the non-dimensional heat release rate $Q_{D}{ }^{*}$ of less than 1 , as shown in Fig. 3. This should be caused by the increase of soot yield, namely considerable amount of evaporated fuel could not contribute to the combustion heat generation. However, the soot yield data are not always clear for large oil fires. Large multiple fires which are merging or swirling can entrain much more fresh air into the upward heated flow, containing un-combusted fuel, compared to one single large fire. In multiple fires, the oil tank steel is significantly heated by the adjacent fires, which can increase the 
evaporation rate of the fuel and cause the heat release rate to increase. Thus, in this study, various cases of heat release rates are examined, although it is unknown if the enhanced heat release rate due to the merging and swirling flow can increase in several times compared to that of one single fire, as indicated in the laboratory experiments.

However, one problem is that large oil fires produce large amounts of soot and thus the real heat release rate is uncertain and must be far smaller than that calculated by the fuel evaporation rate. This fact is different from that in reduced scale fires experiments, where merged fires and fire whirls easily resulted in several times of fuel burning rate, in comparison to one single fire. Thus, in this study, the constant heat release rate model is used and the heat release rate per unit area have been varied from 1000 to $7000 \mathrm{~kW} / \mathrm{m}^{2}$.
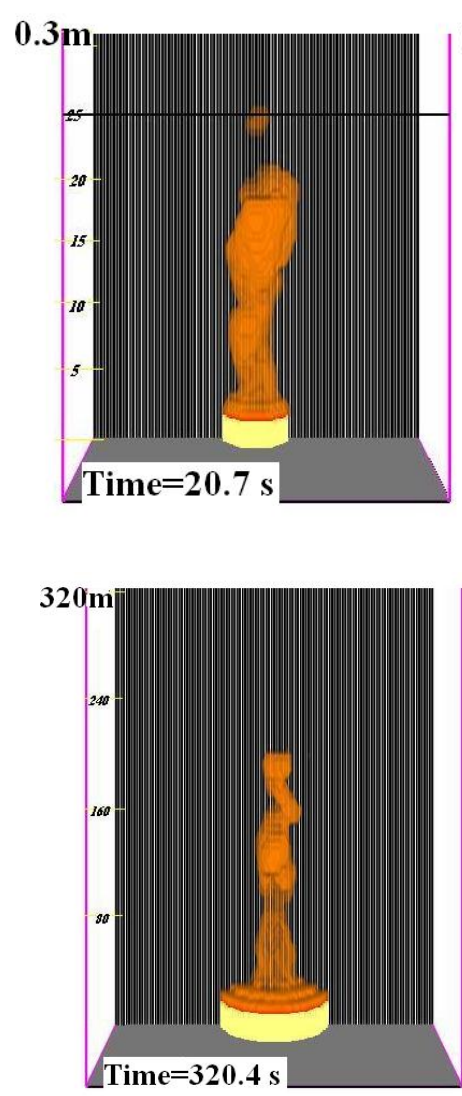

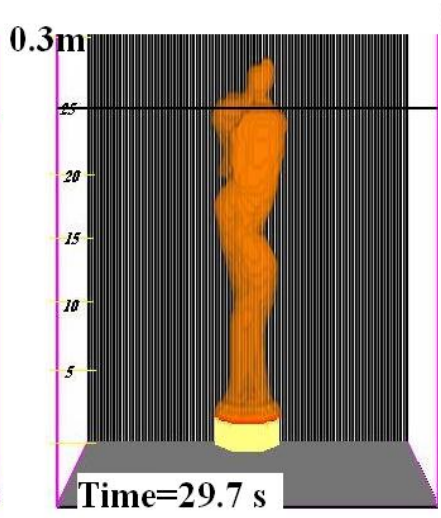

(a)
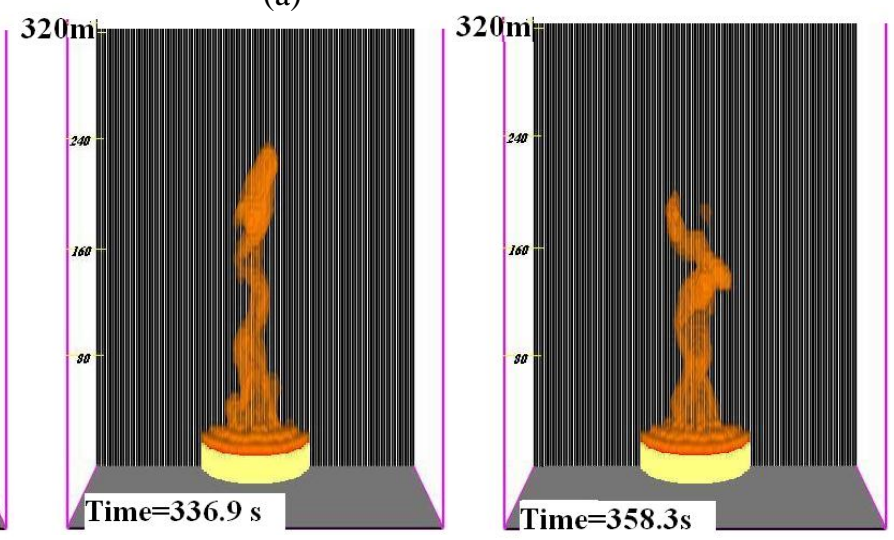

(b)

Fig. 2. Time variation of simulated fire profiles, displayed by heat release rate distribution: (a) $D=0.05 \mathrm{~m}$, $q=1000 \mathrm{~kW} / \mathrm{m}^{2}$; (b) $D=80 \mathrm{~m}, q=1500 \mathrm{~kW} / \mathrm{m}^{2}$.

\section{RESULTS OF CFD SIMULATIONS}

Fire Merging of Oil Tank Fires

\section{Interaction between Two Oil Tank Fires and $(2 \times 2)$ Oil Tank Fires}

The interactions between two oil tank fires and $(2 \times 2)$ oil tank fires are examined, while varying the heat release rate and the tank-to-tank distance, without any wind supply. The values of fuel evaporation rate for the huge fires (e.g. $D=80 \mathrm{~m}$ ), are generally $5-6 \mathrm{~mm} / \mathrm{min}$, which corresponds to the heat release rate per area $\mathrm{q}=3000-4000 \mathrm{~kW} / \mathrm{m}^{2}$, if the fuel is fully burnt, but considerable amount of evaporated fuel must change into soot. Simulations showed that when $q=1000-4000 \mathrm{~kW} / \mathrm{m}^{2}$ and $L$ among $100-240 \mathrm{~m}$, the interaction and merging between two oil tank fires and $(2 \times 2)$ oil tank fires are weak. However, one test 
simulation, using combustion model of n-heptane by FDS v4, has shown considerable interaction for these cases, which may be different from the constant heat release model.

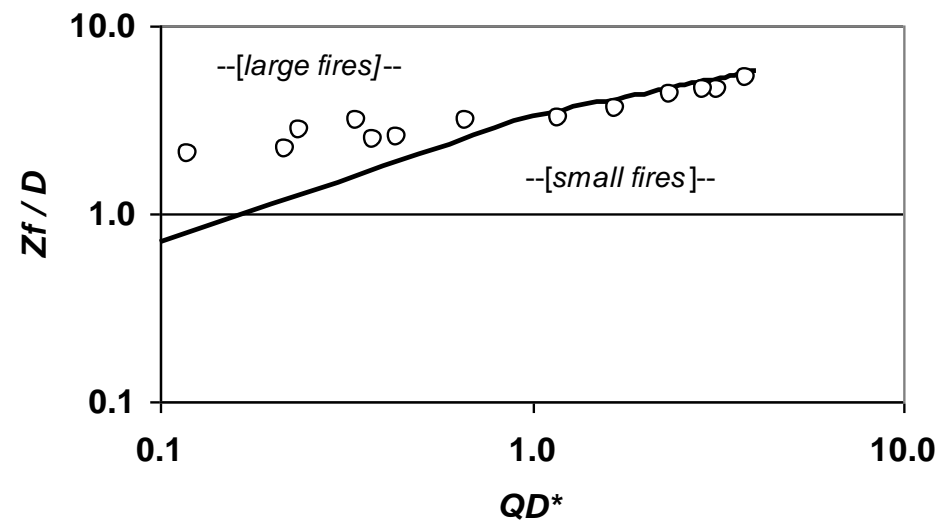

Fig. 3. Relationship between non-dimensional flame height and non-dimensional heat release rate. Open circles: by FDS v4, solid line: by Eq. 1 to 3.

\section{Interaction Among $(3 \times 3),(2 \times 7)$ and $(5 \times 5)$ Oil Tank Fires}

In the $(3 \times 3)$ at $q=4400 \mathrm{~kW} / \mathrm{m}^{2},(2 \times 7)$ at $q=3000 \mathrm{~kW} / \mathrm{m}^{2}$ and $(5 \times 5)$ at $q=3100 \mathrm{~kW} / \mathrm{m}^{2}$, where the tank-to-tank distance is $160 \mathrm{~m}$ respectively, considerably strong interactions causing merging flow are observed as shown in Fig. 4. In addition, at the heat release rates ranging from $q=3000-5000 \mathrm{~kW} / \mathrm{m}^{2}$ and $L=160 \mathrm{~m}$ in the simulations, strong interactions similar to the merging flows in Fig. 4 are produced. At $q=1500$ or $2000 \mathrm{~kW} / \mathrm{m}^{2}$, considerable interactions exist, but merging flow is not clear. For $q$ less than $1000 \mathrm{~kW} / \mathrm{m}^{2}$, no substantial interaction or merging flow is observed. In these cases, when tank-to-tank distance is more than $240 \mathrm{~m}$, no obvious interaction is observed.

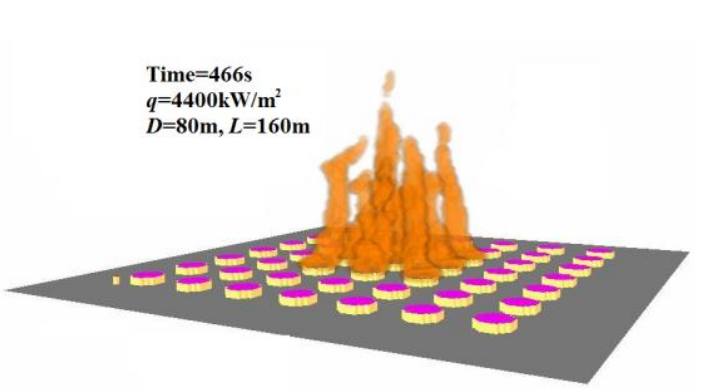

(a)

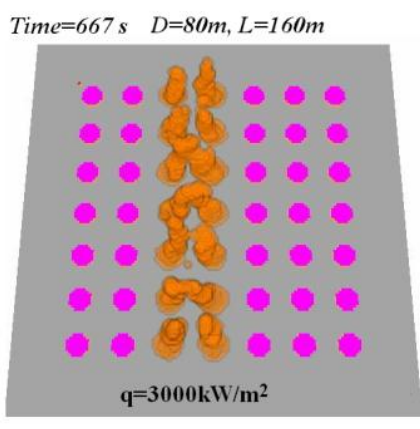

(b)

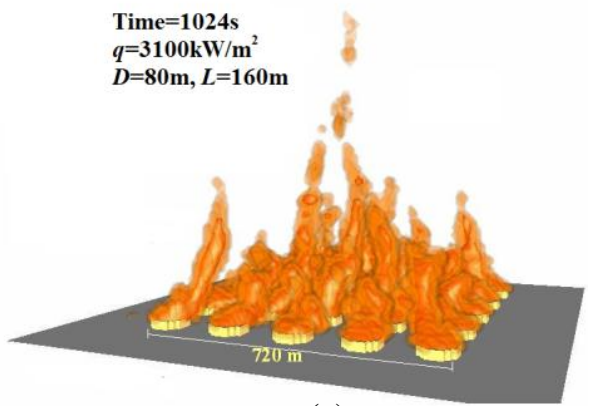

(c)

Fig. 4. Burning profiles, displayed by heat release rate distribution of oil tank fires: (a) $3 \times 3$ oil tanks - side view; (b) $2 \times 7$ oil tanks - plan view; (c) $5 \times 5$ oil tanks - side view. 


\section{Interaction among $(7 \times 7)$ Oil Tank Fires}

For $q=1000 \mathrm{~kW} / \mathrm{m}^{2}$ and $L=160 \mathrm{~m}$, no substantial interaction or merging flow is observed, as shown in Fig. 5a. However, if heat release rate per area exceeds $1500 \mathrm{~kW} / \mathrm{m}^{2}$, and interactions between fires are observed, as shown in Fig. 5b. For $q=3000-5000 \mathrm{~kW} / \mathrm{m}^{2}$, strong interactions causing strong merging flows fires are observed, as shown in Figs. 5c and d. The images shown in Fig. 5 correspond to the evolution of the fire merging process, namely the fire merging becomes strong with the increase of heat generation.

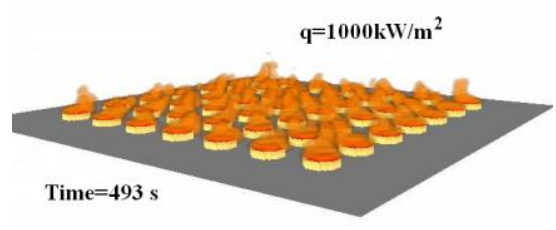

(a)

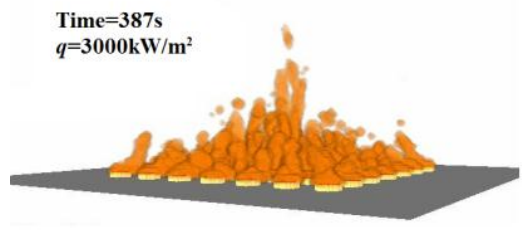

(c)

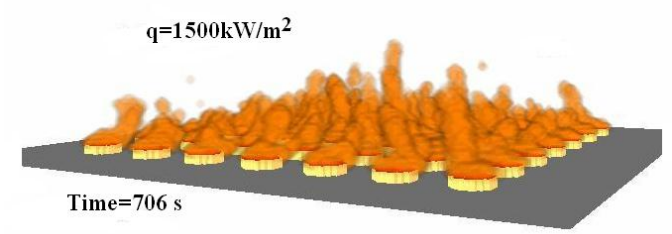

(b)

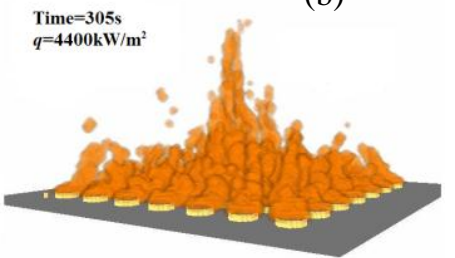

(d)

Fig. 5. Evolution of fire merging process in $(7 \times 7)$ oil tank fires, $D=80 \mathrm{~m}, L=160 \mathrm{~m}$.

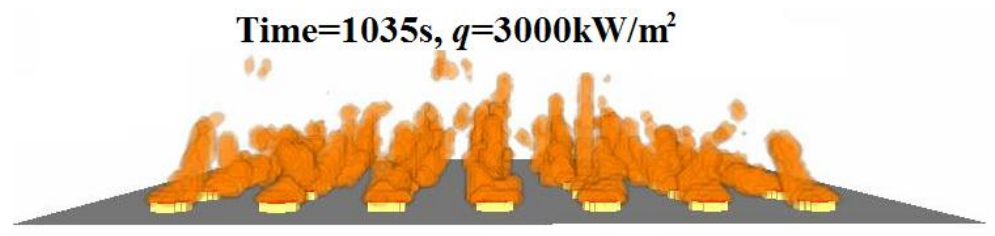

Fig. 6. Fire profile of $(7 \times 7)$ oil tank fires, $D=80 \mathrm{~m}, L=240 \mathrm{~m}$.

As mentioned above, the tank-to-tank distance $L$ can significantly affect the fire merging phenomena in array fires. For the tank-to-tank distance less than $160 \mathrm{~m}$ and $q=3000 \mathrm{~kW} / \mathrm{m}^{2}$, fire merging can be observed, while no apparent interaction is observed for $L=240 \mathrm{~m}$ and at $q=3000 \mathrm{~kW} / \mathrm{m}^{2}$, as shown in Fig. 6. Even when the heat release rate per area more than $4000 \mathrm{~kW} / \mathrm{m}^{2}$, no significant merging is observed. Therefore, the tank-to-tank distance $L=240 \mathrm{~m}$ can be considered as the threshold for the fire merging process for an array of $(7 \times 7)$ with $D=80 \mathrm{~m}$. Although there has no case in windy conditions, since this study does not use the combustion model related to wind speed, the fires corresponding to Fig. 6 may also be enhanced by wind to get merged. In cases of non-merging fires, the negative pressure center near the ground is vague, while in merging fire cases, such as in Figs. $5 \mathrm{c}$ and d, the negative pressure center is clear and the fires may be able to induce fire whirl, if adequate wind is applied.

\section{Fire Whirl Generation in a Fire Array Due to Shear Wind}

\section{Swirling Flows in Single Fire}

Single fire is placed in the way shown in Fig. 7, where one edge of circular surroundings of oil tank $(D=80 \mathrm{~m})$ is on the boundary of wind flow, a shear wind is supplied to a fire. However, the wind supply width is set at $80 \mathrm{~m}$, since $300 \mathrm{~m}$ width supplies too much air against the total heat release rate. Although the conditions are quite limited, there are some cases to cause a swirling flow. For example, at the wind speed of 4 to $7 \mathrm{~m} / \mathrm{s}$ and the heat release rate per area between 3000 and $4000 \mathrm{~kW} / \mathrm{m}^{2}$, swirling flows can be observed, where a vortex exists in the burn area of oil tank, the ambient air is entrained into the fire and the pressure reduces to negative minimum value in the swirling vortex center. Figure 7 shows a swirling behavior at $U=5 \mathrm{~m} / \mathrm{s}$ and $q=3000 \mathrm{~kW} / \mathrm{m}^{2}$. When the wind speed is larger than $8 \mathrm{~m} / \mathrm{s}$, the fire is blown 
down toward the ground and the lowest pressure center moves out of the fire, which never causes a long swirling flow of fire. When the wind speed is smaller than $4 \mathrm{~m} / \mathrm{s}$, a vortex is vague and thus the swirling motion is unclear, which indicates that there is insufficient entrainment to cause the swirling flow. At the heat release rate per area of $2000 \mathrm{~kW} / \mathrm{m}^{2}$, vortex and swirling flow are present, but very weak. At any heat release rate per area less than $1500 \mathrm{~kW} / \mathrm{m}^{2}$, a weak vortex exists, but the swirling motion is vague. However, if the fire grows from 1500 to $2000-3000 \mathrm{~kW} / \mathrm{m}^{2}$, a weak vortex can also grow, together with the growth of swirling flow. If the wind at the boundary stops, the swirling motion also decays. However, if the wind exists and the oil burns continuously, the swirling motion can continue, together with the enhanced burning rate and radiation that will increase the heat transfer to the neighboring oil tanks.

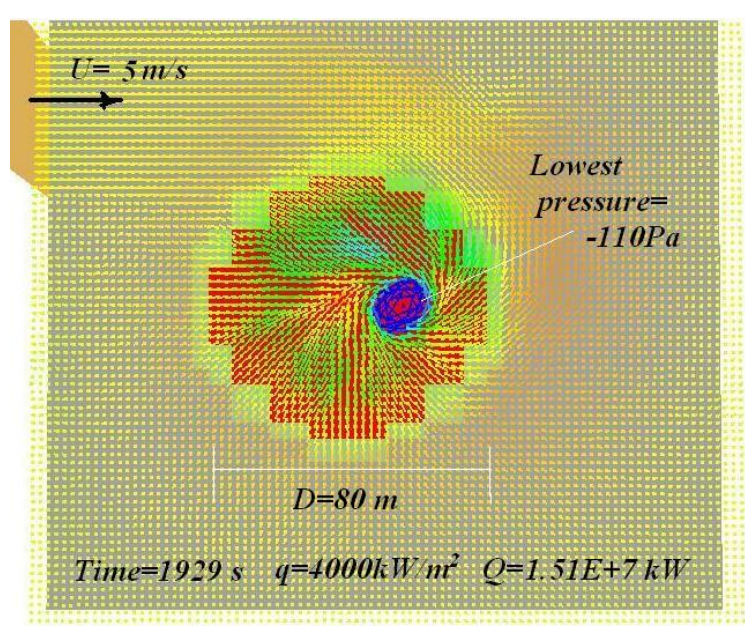

(a)

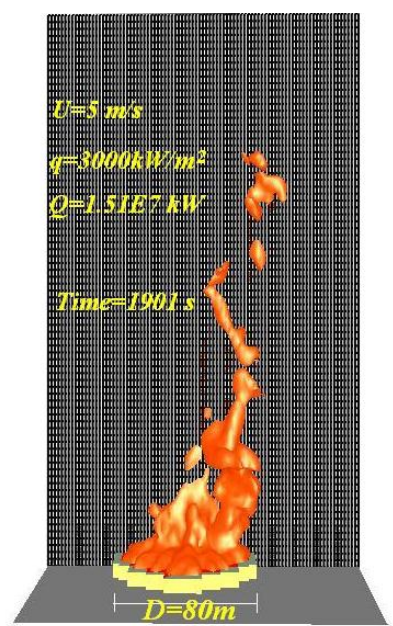

(b)

Fig. 7. Fire profile of single oil tank fires, $D=80 \mathrm{~m}, U=5 \mathrm{~m} / \mathrm{s}, q=3000 \mathrm{~kW} / \mathrm{m}^{2}$ : (a) plan view by velocity and pressure field at the height of $30 \mathrm{~m}$; (b) side view by mixture fraction field.

\section{Swirling Flows in $(2 \times 2),(3 \times 2),(3 \times 3)$ and $(5 \times 3)$ Arrayed Fires}

Wind conditions for single oil tank fire to cause a fire whirl are quite limited, while in cases of multiple fires, the possibility is slightly wide, since the fire area is larger and the merging fires can easily swirl. When the wind speed $U$ is more than $5 \mathrm{~m} / \mathrm{s}$ in the $(2 \times 2),(3 \times 2),(3 \times 3)$ and $(5 \times 3)$ arrays at $q=3000 \mathrm{~kW} / \mathrm{m}^{2}, D=80 \mathrm{~m}$ and $L=160 \mathrm{~m}$, a vortex appears in the fires. Fig. 8 a corresponds to the lower limit of the wind speed, $U=5 \mathrm{~m} / \mathrm{s}$, to cause a fire whirl for $(2 \times 2)$ array fire at $q=3000 \mathrm{~kW} / \mathrm{m}^{2}$. However, $U=12 \mathrm{~m} / \mathrm{s}$ is out of the upper limit to cause a fire whirl, since the vortex is out of the fire area, where a vortex appearing periodically at the boundary between the fire array edge and the wind edge is blown out of the array, as shown in Fig. 8b. At wind speed between 5 and $9 \mathrm{~m} / \mathrm{s}$ for $(2 \times 2)$ array fire and $q=3000 \mathrm{~kW} / \mathrm{m}^{2}$, a vortex appearing in the array fires causes a continuous swirling flow, entraining each flame into the center of the vortex. As shown in single oil tank fire, in these cases, the lowest and negative pressure center is also in the vortex center near the ground. At a wind speed less than $5 \mathrm{~m} / \mathrm{s}$, the swirling flow is not significant, although a small vortex appears. When $q$ is less than $1500 \mathrm{~kW} / \mathrm{m}^{2}$, the vortex and swirling motion exist at the wind speed of 5 to $10 \mathrm{~m} / \mathrm{s}$, but they are not as significant as those in Fig. 8a. At $q=2000 \mathrm{~kW} / \mathrm{m}^{2}$, a vortex and swirling motion are clearly observed in the array, although they are fairly weak compared to those at $q=3000 \mathrm{~kW} / \mathrm{m}^{2}$. At $q=4000 \mathrm{~kW} / \mathrm{m}^{2}$ or above, a strong swirling flow in the array is observed, although there are some cases where the entrained air is insufficient to generate the swirling flow. Therefore, too strong wind and insufficient wind are unable to generate the swirling fires, depending on the total heat release rate. In the cases of $(2 \times 3)$ oil tank arrays, where the wind speed $U$ is more than 5 to $10 \mathrm{~m} / \mathrm{s}$ in the $(2 \times 2)$ and at $q=3000 \mathrm{~kW} / \mathrm{m}^{2}, D=80 \mathrm{~m}$ and $L=160 \mathrm{~m}$, a swirling flow is produced. In the cases of $(3 \times 3)$ array fires, the lower limit and upper limit of wind speed to cause a fire whirl are 7 and $11 \mathrm{~m} / \mathrm{s}$, respectively, as shown in Figs. $8 \mathrm{c}$ and d. Also, in the cases of $(5 \times 3)$ array fires, the two limits are 8 and $12 \mathrm{~m} / \mathrm{s}$, respectively. 


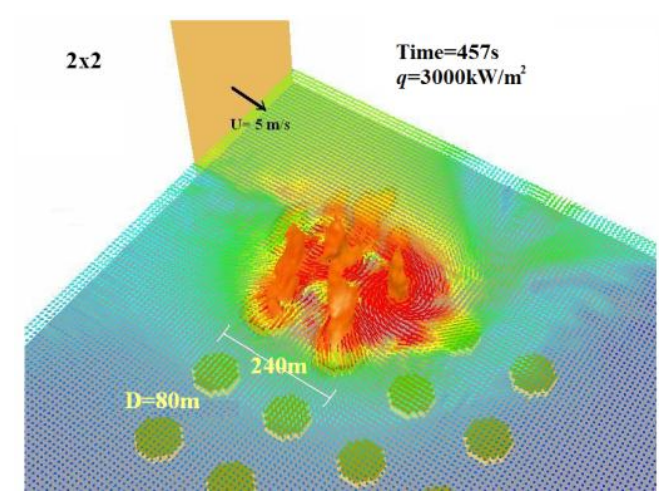

(a)

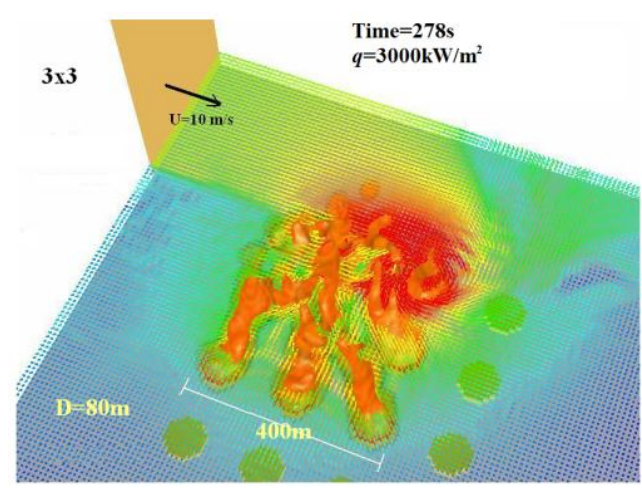

(c)

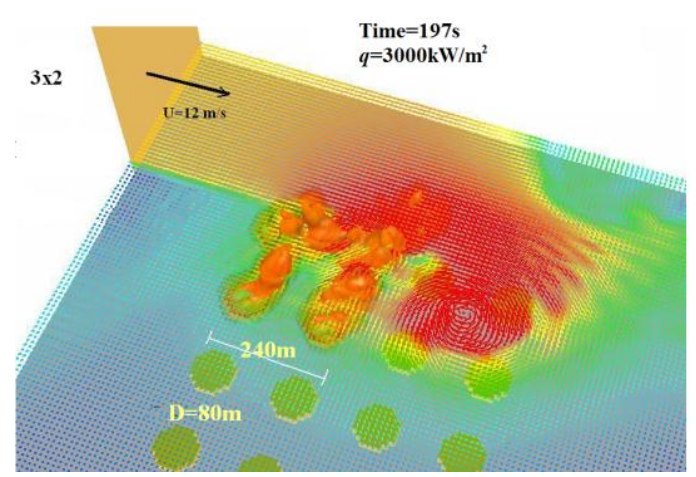

(b)

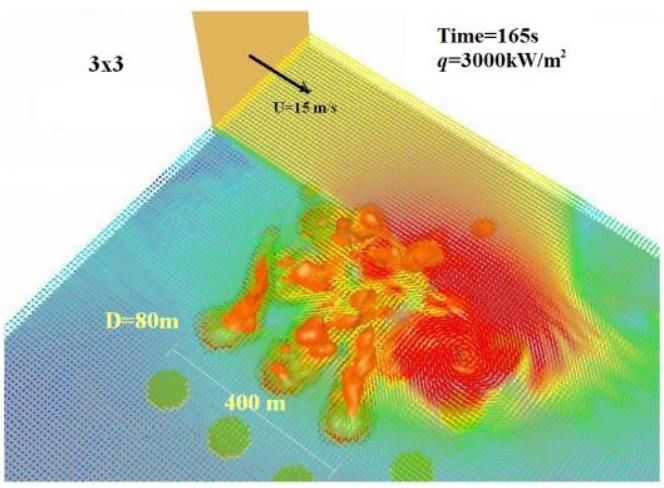

(d)

Fig. 8. Fire profiles of $(2 \times 2)$ and $(3 \times 3)$ oil tank fires, $D=80 \mathrm{~m}, L=160 \mathrm{~m}, q=3000 \mathrm{~kW} / \mathrm{m}^{2}$ : (a) $U=5 \mathrm{~m} / \mathrm{s}$; (b) $U=12 \mathrm{~m} / \mathrm{s}$; (c) $U=10 \mathrm{~m} / \mathrm{s}$; (d) $U=15 \mathrm{~m} / \mathrm{s}$.

Swirling Flow in $(5 \times 5)$ Arrayed Fires

In the $(5 \times 5)$ fire array, a vortex is created in the fire array at $U=10 \mathrm{~m} / \mathrm{s}$ and $q=3000 \mathrm{~kW} / \mathrm{m}^{2}$, but at $20 \mathrm{~m} / \mathrm{s}$, a vortex appears at the boundary and finally the vortex is blown out of the fire array, similar to those in single, $(2 \times 2)$ and $(3 \times 3)$ arrays, while at the wind speeds between 7 to $15 \mathrm{~m} / \mathrm{s}$, the vortex continuously exists in the fire array and the swirling flow is stable, as shown in Fig. 9 at $q=3000 \mathrm{~kW} / \mathrm{m}^{2}$. When $U$ is less than $7 \mathrm{~m} / \mathrm{s}$, a small vortex appears, but the swirling flow is not as significant as that shown in Fig. 9. The effects of $q$ between $1000 \mathrm{~kW} / \mathrm{m}^{2}$ to $4000 \mathrm{~kW} / \mathrm{m}^{2}$ is similar to those in the arrays $(2 \times 2)$ and $(3 \times 3)$, while the maximum wind speeds required to maintain a swirling flow inside the array becomes larger than those in $(2 \times 2)$ and $(3 \times 3)\left(\right.$ e.g. up to $20 \mathrm{~m} / \mathrm{s}$ at $\left.q=3000 \mathrm{~kW} / \mathrm{m}^{2}\right)$.
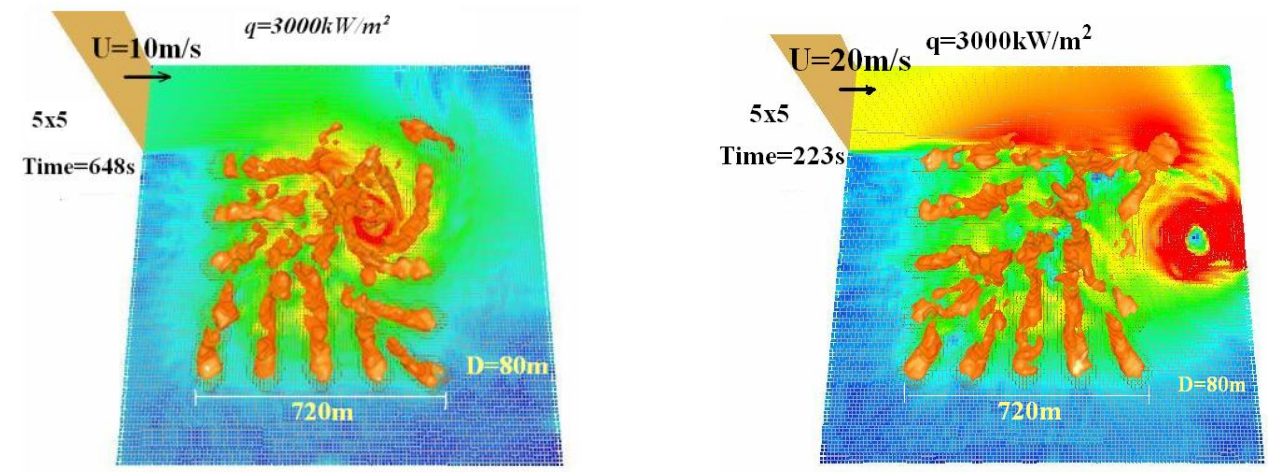

Fig. 9. Fire profiles, displayed by velocity and mixture fraction field, of $(5 \times 5)$ oil tank fires, $D=80 \mathrm{~m}, L=160 \mathrm{~m}$ (plan view). 


\section{Swirling Flows in $(7 \times 7)$ Oil Tank Fires}

A clear vortex is generated in each $(7 \times 7)$ array, in those cases such as $(1) q=1000 \mathrm{~kW} / \mathrm{m}^{2}$ and $U=10 \mathrm{~m} / \mathrm{s}$, (2) $q=1000 \mathrm{~kW} / \mathrm{m}^{2}$ and $U=15 \mathrm{~m} / \mathrm{s}$ and (3) $q=1500 \mathrm{~kW} / \mathrm{m}^{2}$ and $U=10 \mathrm{~m} / \mathrm{s}$. Figure 10 shows the swirling behavior in the array at $q=1500 \mathrm{~kW} / \mathrm{m}^{2}$ and $U=10 \mathrm{~m} / \mathrm{s}$, while the flame height is not so long. However, if the fires are heated mutually and the heat release rate increases to $2000-3000 \mathrm{~kW} / \mathrm{m}^{2}$, the flame should become higher, which corresponds to the growing process of fire merging and fire whirl, as mentioned above. Namely, this stage can grow in intensity to a stage with a long fire whirl. When $q=2000$ $4000 \mathrm{~kW} / \mathrm{m}^{2}$ and $U=15-25 \mathrm{~m} / \mathrm{s}$, a clear vortex and a long swirling flow appear in the $(7 \times 7)$ array. Figure 11 shows the profile of a fire whirl at $D=80 \mathrm{~m}, L=160 \mathrm{~m}, U=22 \mathrm{~m} / \mathrm{s}$ and $q=4410 \mathrm{~kW} / \mathrm{m}^{2}$. When the tank-to-tank distance $L$ is $240 \mathrm{~m}$ and $q$ is less than $4000 \mathrm{~kW} / \mathrm{m}^{2}$, a weak vortex is generated, but no obvious swirling flow is observed in the fire array. At $q=5000 \mathrm{~kW} / \mathrm{m}^{2}$, a clear swirling flow can be observed in the fire array. Therefore, at $L=240 \mathrm{~m}$, if $q$ is more than $4000 \mathrm{~kW} / \mathrm{m}^{2}$, a swirling flow can be produced. In one extreme case of $(17 \times 17)$ array, the upward fire flow is considerably strong. Therefore, the wind supply width is set at $500 \mathrm{~m}$ and the height is $500 \mathrm{~m}$. For this wind supply, the lower limit to cause a fire whirl is $24 \mathrm{~m}$ and the upper limit to cause a fire whirl is $30 \mathrm{~m} / \mathrm{s}$ at $q=3000 \mathrm{~kW} / \mathrm{m}^{2}$.

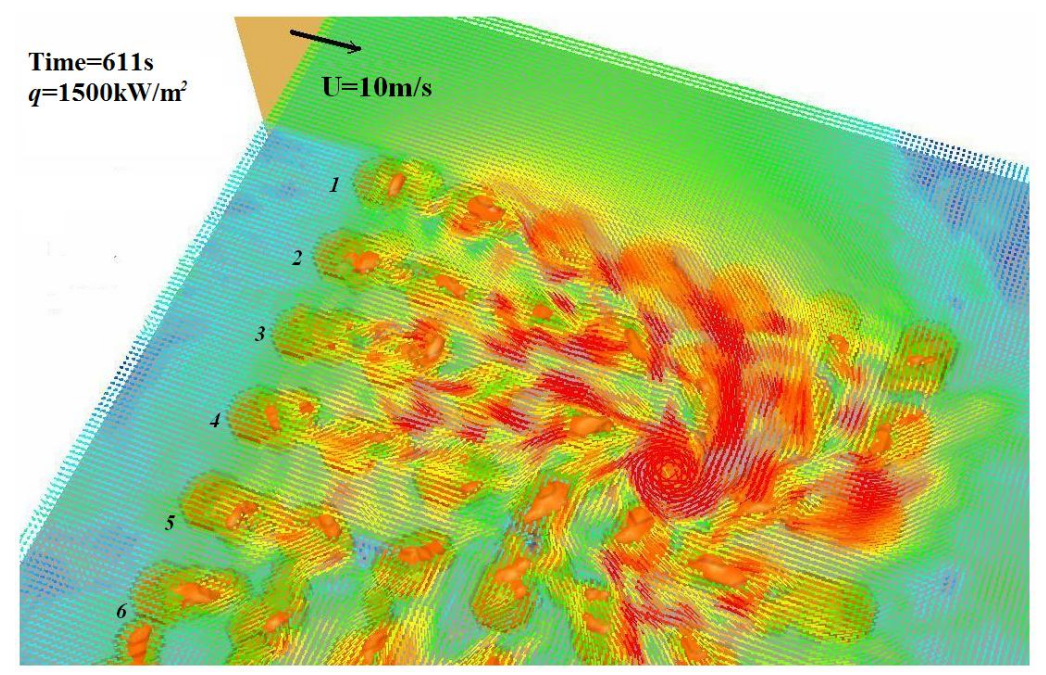

Fig. 10. Fire profiles (plan view), displayed by velocity, of $(7 \times 7)$ oil tank fires, $D=80 \mathrm{~m}, L=160 \mathrm{~m}$, $U=10 \mathrm{~m} / \mathrm{s}, q=1500 \mathrm{~kW} / \mathrm{m}^{2}$.
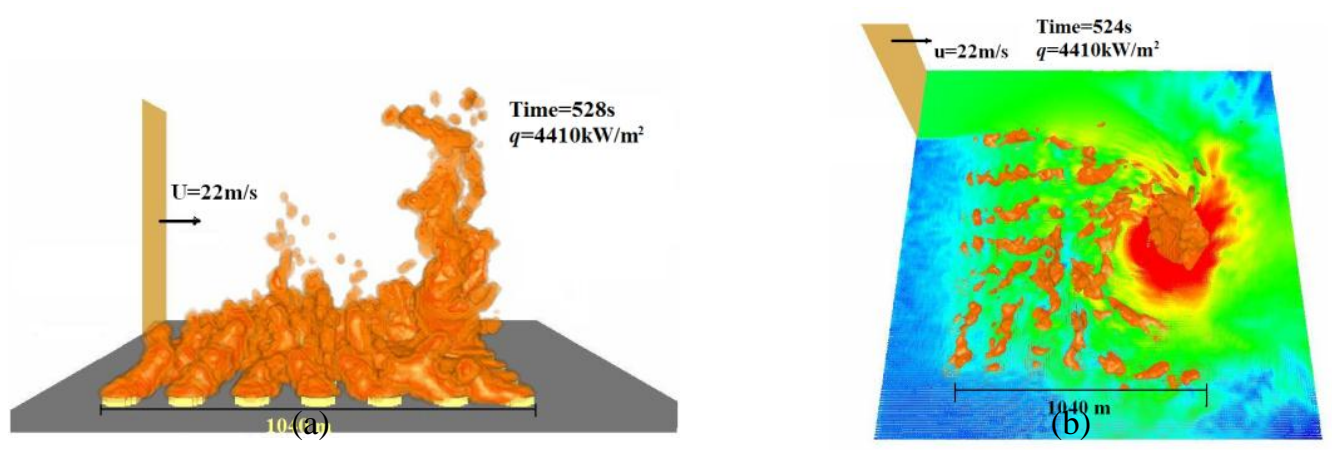

Fig. 11. Fire profiles of $(7 \times 7)$ oil tanks, $D=80 \mathrm{~m}, L=160 \mathrm{~m}, U=22 \mathrm{~m} / \mathrm{s}, q=4410 \mathrm{~kW} / \mathrm{m}^{2}$ : (a)

Horizontal view by heat release rate distribution; (b) Plan view by wind velocity distribution;

\section{Relationship between Wind Mass Flow Rate and Total Heat Release Rate to Cause a Fire Whirl}

The simulations mentioned above have shown that a swirling fire is created not only in single oil tank fire, but also in multiple array fires. The fire whirl generation may be governed by the ratio between the amount 
of entrained cool air and the upward hot air flow due to the total heat release rate of fires, which has been examined in our previous studies $[12,13]$. However, at this time, it is difficult to separate how many percent within in the supplied mass flow rate can contribute to the entrainment into the fire whirl and how many percent of the upward heated air flow rate caused by the total heat release rate can contribute to the formation of fire whirl, since the entrained air is soon mixed with the heated air flow. In this study, the air supply area into the fire whirl has been limited to the area of $300 \mathrm{~m} \times 300 \mathrm{~m}$, but the air outside of the $300 \mathrm{~m} \times 300 \mathrm{~m}$ might have contributed to the air entrained into a fire whirl. Further detailed analysis about this contribution will be in the future study. Table 1 shows the upper limit and lower limit of wind velocity and the supplied mass flow rate to generate a fire whirl as a function of the total heat release rate. The wind blowing area at the boundary is $300 \mathrm{~m}$ in height and $300 \mathrm{~m}$ in width, except for single fire and $(17 \times 17)$ array fires, as mentioned above. In this study, only the relationship between the supplied air mass flow rate in the $300 \times 300 \mathrm{~m}$ area and the total heat release rate is used, which is shown in Fig. 12, using the data in Table 1. A correlation relating to both the upper and lower limit is expressed in Fig. 12 and the corresponding equation is

$M=1232.4 Q^{0.3517}$

In other way, if the wind speed is employed as the vertical axis in Fig. 12, the following equation is given, in which single fire and $(17 \times 17)$ array fire can be included.

$U=0.0137 Q^{0.3517}$

Using this simulation, fire merging and fire whirls may be predicted based on the generated heat release rates of oil depot fires.

Table 1. Range of wind speed required to generate a swirling flow in an array.

\begin{tabular}{|c|c|c|c|c|c|c|c|}
\hline & & & & minimum & maximum & minimum & maximum \\
\hline & fires & $q\left(\mathrm{~kW} / \mathrm{m}^{2}\right)$ & $Q(\mathrm{~kW})$ & $U(\mathrm{~m} / \mathrm{s})$ & $U(\mathrm{~m} / \mathrm{s})$ & $M\left(\mathrm{~m}^{3} / \mathrm{s}\right)$ & $M\left(\mathrm{~m}^{3} / \mathrm{s}\right)$ \\
\hline 1 & single & 3000 & $1.51 \times 10^{7}$ & 4.0 & 5.0 & $*$ & $*$ \\
\hline 2 & single & 4000 & $2.01 \times 10^{7}$ & 4.0 & 6.0 & $*$ & $*$ \\
\hline 3 & $2 \times 1$ & 3000 & $3.02 \times 10^{7}$ & 5.0 & 6.0 & 450000 & 540000 \\
\hline 4 & $2 \times 2$ & 2000 & $4.02 \times 10^{7}$ & 6.0 & 9.0 & 540000 & 810000 \\
\hline 5 & $2 \times 2$ & 3000 & $6.03 \times 10^{7}$ & 7.0 & 9.0 & 630000 & 810000 \\
\hline 6 & $3 \times 2$ & 2500 & $7.54 \times 10^{7}$ & 7.0 & 9.0 & 630000 & 810000 \\
\hline 7 & $3 \times 3$ & 2000 & $9.05 \times 10^{7}$ & 7.0 & 10.0 & 630000 & 900000 \\
\hline 8 & $3 \times 3$ & 3000 & $1.36 \times 10^{8}$ & 7.0 & 11.0 & 630000 & 990000 \\
\hline 9 & $5 \times 3$ & 3000 & $2.26 \times 10^{8}$ & 8.0 & 12.0 & 720000 & 1080000 \\
\hline 10 & $5 \times 5$ & 2000 & $2.51 \times 10^{8}$ & 10.0 & 15.0 & 900000 & 1350000 \\
\hline 11 & $5 \times 5$ & 3000 & $3.77 \times 10^{8}$ & 9.0 & 18.0 & 810000 & 1620000 \\
\hline 12 & $5 \times 5$ & 4000 & $5.03 \times 10^{8}$ & 10.0 & 22.0 & 900000 & 1980000 \\
\hline 13 & $7 \times 7$ & 2000 & $4.93 \times 10^{8}$ & 14.0 & 20.0 & 1260000 & 1800000 \\
\hline 14 & $7 \times 7$ & 3000 & $7.39 \times 10^{8}$ & 12.0 & 25.0 & 1080000 & 2250000 \\
\hline 15 & $7 \times 7$ & 4000 & $9.85 \times 10^{8}$ & 15.0 & 25.0 & 1350000 & 2250000 \\
\hline 16 & $7 \times 7$ & 7000 & $1.72 \times 10^{9}$ & 20.0 & 30.0 & 1800000 & 2700000 \\
\hline 17 & $17 \times 17$ & 2000 & $2.91 \times 10^{9}$ & 24.0 & 30.0 & $*$ & $*$ \\
\hline
\end{tabular}




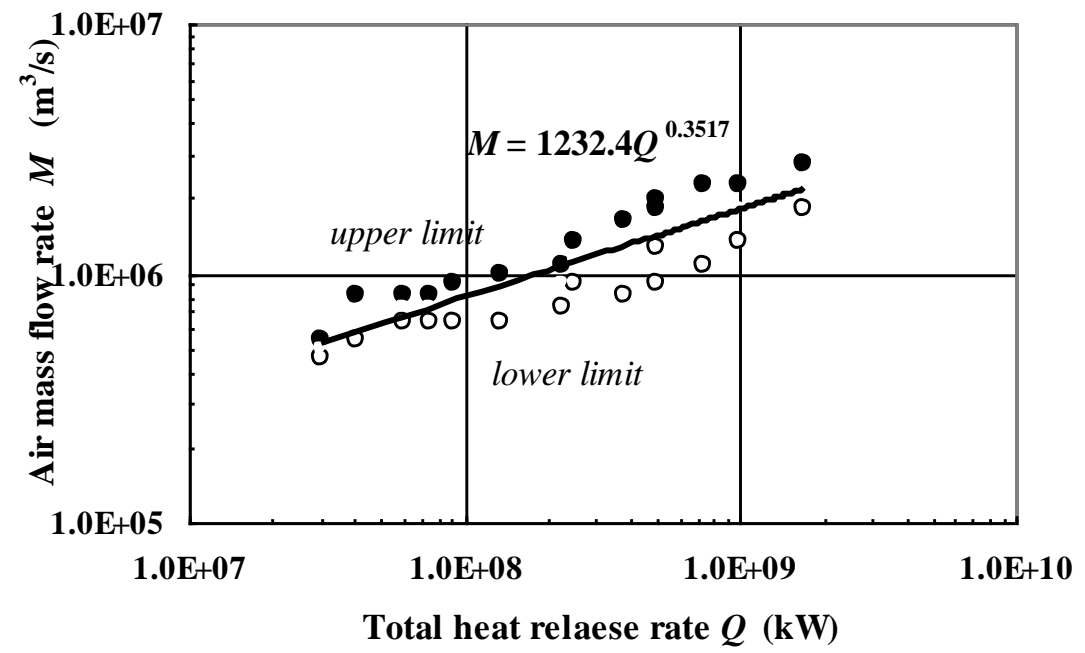

Fig. 12. Relationship between total heat release rate and wind speed to cause swirling flow (solid circles: upper limit of air flow rate; open circles: lower limit of air flow rate).

\section{CONCLUSIONS}

In this study, the fire merging and fire whirl generation in arrayed fires have been examined to specifically determine the conditions for the occurrence of merging fires and fire whirls. This study was performed by CFD simulations using the software of FDS v4 by NIST, especially for huge oil depot fires, mainly for the $(7 \times 7)$ arrayed oil tanks. Each tank is $80 \mathrm{~m}$ in diameter with a uniform tank-to-tank distance of $160 \mathrm{~m}$. Due to the combustion problem of oil tank fires such as soot yield problem, the constant heat release model, with $q=1000$ to $5000 \mathrm{~kW} / \mathrm{m}^{2}$, was used in this study. The generation of fire merging and fire whirls was investigated by applying various heat release rates and tank-to-tank distances. The results showed that at heat release rate per unit area of less than $2000 \mathrm{~kW} / \mathrm{m}^{2}$, no significant interaction resulting in fire merging flows was observed. At $q=3000-5000 \mathrm{~kW} / \mathrm{m}^{2}$, strong interactions that produce merging flows are apparent. The profiles of fires with heat release rate ranging from $1000-5000 \mathrm{~kW} / \mathrm{m}^{2}$ correspond to the evolving growth of fire merging along with the fire growth in the $(7 \times 7)$ array. The tank-to-tank distance $L=240 \mathrm{~m}$ can be considered as the threshold for fire merging. In cases of non-merging fires, the negative pressure center near the ground is vague, while in merging fire cases, the negative pressure center is clear, which is also similar in swirling fires. Namely the lowest negative pressure center is in the center of a fire whirl and a vortex center. It is concluded that fire whirl generation is governed by the ratio between the amount of wind supply and the total heat release rate of fires. If the total heat release rate is stronger than the applied wind, the swirling flow would be weak, and if the applied wind is significantly stronger than the total heat release rate, a vortex existing in the lowest pressure center is pushed away toward the boundary without any swirling flow generation. When the ratio between the upward heated flow and the entrained air is comparable, a vortex in swirling flow can last for a long period of time. The correlation between supplied air mass flow rate and the total heat release rate is established.

\section{ACKNOWLEDGEMENT}

This work was sponsored by National Natural Science Foundation of China under Grants 51076148 and R\&D Special Fund for Public Welfare Industry (forestry, 200704027). Naian Liu was supported by the Fok Ying Tung Education Foundation. Haixiang Chen was supported by National Natural Science Foundation of China under Grant 50806070. Koyu Satoh was supported by Chinese Academy of Sciences Visiting Professorship for Senior International Scientists (Grant No. 2009z2-31). Correspondence to this paper should be addressed to Prof. Naian LIU, liunai@ustc.edu.cn.

\section{REFERENCES}

[1] Persson. H., Lönnermark A., "Tank Fires-Review of fire incidents 1951-2003”, BRANDFORSK Project 513-021, SP Fire Technology. SP REPORT 2004:14, Swedish National Testing and Research Institute. 
[2] Lois, E. and Switchenbank J., "Fire Hazards in Oil Tank Arrays in a Wind", Proceedings of $17^{\text {th }}$ (International) on Combustion, Leeds, Combustion Institute, Pittsburg, PA, 1979, pp.1087-1098, http://dx.doi.org/10.1016/s0082-0784(79)80104-6

[3] Shaluf, I. M., and Abdulla S., (2010), "An Overview on ADCO Crude Oil Storage Tanks", Disaster Prevention and Management, Buncefield Investigation Press Releases, 19(3): 370-383, http://dx.doi.org/10.1108/09653561011052538.

[4] "Storage Tank Explosion and Fire Glenpool, Oklahoma April 7, 2003", 2004, NTSB/PAR-4/02 PB2004-916502 Notation 7666, National Transportation Safety Board.

[5] Baldwin, R., (1968) Flame Merging in Multiple Fires, Combustion and Flame, 12: 318-324, http://dx.doi.org/10.1016/0010-2180(68)90036-9.

[6] Thomas, P.H. Baldwin R., and Heselden, J.M., "Buoyant Diffusion Flames: Some Measurements of Air Entrainment, Heat Transfer, and Flame Merging", Proceedings of the $10^{\text {th }}$ Symposium (International) on Combustion, 1965, 983-996, http://dx.doi.org/10.1016/s0082-0784(65)80241-7

[7] Liu, N.A., Liu, Q., Deng, Z., Satoh, K., and Zhu, J., (2007) Burn-out Time Data Analysis on Interaction Effects among Multiple Fires in Fire Arrays, Proceedings of the Combustion Institute, 31(2): 2589-2597, http://dx.doi.org/10.1016/j.proci.2006.08.110 .

[8] Liu, N.A., Liu, Q, Lozano, J.S., Shu, L.F., Zhang, L.H., Zhu, J.P., Deng, Z.H., and Satoh, K. (2009), Global burning rate of square fire arrays: Experimental correlation and interpretation, Proceedings of the Combustion Institute. 32: 2519-2526, http://dx.doi.org/10.1016/j.proci.2008.06.086.

[9] Liu, N.A., (2005), "Experimental and Theoretical Investigation on Fire Interactions and the Induced Firewhirls in Square Fire Arrays", Proceedings of Fifth NRIFD International Symposium on Forest Fires, Mitaka, Tokyo, Nov. 2005, 293-301, http://dx.doi.org/10.1016/j.proci.2006.08.110

[10] Satoh, K., Shinohara, M., and Yang, K.T., "Experimental Observations and Analysis of Square Arrays Equidistant Multiple Fires", Proceedings of Asia-Oceania Fire Safety Symposium, Singapore, 1999, pp. 517-528.

[11] Satoh, K., Liu, N., Zhu, J., and Yang, K.T., "Experiments and Analysis of Interaction among Multiple Fires in Equidistant Fire Arrays", Proceedings of 2005 ASME/HTD, San Francisco, California, 2005, HT2005-72494, http://dx.doi.org/10.1115/HT2005-72494

[12] Satoh, K., Liu, N., Liu, Q., and Yang, K.T., "Numerical and Experimental Study of Merging Fires in Square arrays", Proceedings of IMECE2007, 2007 ASME International Mechanical Engineering Congress and Exposition, 2007, Seattle, Washington, USA, IMECE2007-43220. 461472, http://dx.doi.org/10.1115/IMECE2007-43220

[13] Satoh, K., Liu, N., Liu, Q., and Yang, K.T., "Numerical and Experimental Study of Fire Whirl Generated in 15 x 15 square Array Fires Placed in Cross Wind", Proceedings of IMECE2008, 2008 ASME International Mechanical Engineering Congress and Exposition, 2008, Boston, Massachusetts, USA, IMECE2008-66865, http://dx.doi.org/10.1115/IMECE2008-66865

[14] Satoh, K., Liu, N., Liu, Q., and Yang, K.T., "Preliminary Study of Fire Spread in Cities and Forests, using PMMA Specimen as a Fuel in CFD Simulations", Proceedings of 2009 ASME/HTD, Lake Buena Vista, Florida, USA, 2009, IMECE2009-10037, http://dx.doi.org/10.1115/IMECE2009-10037

[15] Blinov, V.I. and Khudyakov G.N., "Diffusion Burning of Liquids", US Army Translation NTIS No. AD196762., Izdatel'stvo Akademii Nauk SSSR: Moscow. 1961, 149-158 (in Russian).

[16] Weng, W., Kamikawa, D., Fukuda, Y., Hasemi, Y., and Kagiya, K., (2004) Study on Flame Height of Merged Flame From Multiple Fire Sources, Combustion Science and Technology, 176: 2105-2123, http://dx.doi.org/10.1080/00102200490514949 
[17] Babrauskas, V., (1983) Estimating Large Pool Fire Burning Rates, Fire Technology, 19(4): 251261, http://dx.doi.org/10.1007/BF02380810

[18] Atreya, A. and Agrawal, A., (1998) Effect of Heat Loss on Diffusion Flames, Combustion and Flame, 115: 372-382, http://dx.doi.org/10.1016/s0010-2180(97)00364-7

[19] McGrattan, K. B., Baum, H.R., Rehm, R.G., (1996) Numerical Simulation of Smoke Plumes from Large Oil Fires, Atmospheric Environment, 30(24): 4125-4136, http://dx.doi.org/10.1016/1352$\underline{2310(96) 00151-3}$

[20] Baum, H.R., McGrattan, K.B., "Simulation of Oil Tank Fires", Proceedings of $1999\left(8^{\text {th }}\right)$ Interflam, Edinburgh, Scotland, 2, 1999, 1117-1128.

[21] Takahashi, N., Suzuki, M., Dobashi, R., Hirano, T., (1999) Behavior of Luminous Zones Appearing on Plumes of Large-Scale Pool Fires of Kerosene, Fire Safety Journal, 33(1):1-10, http://dx.doi.org/10.1016/s0379-7112(99)00009-0

[22] McGrattan, K.B., Baum, H.R., Hamins, A., "Thermal Radiation from Large Pool Fires", NISTIR 6546, National Institute of Standards and Technology, 2000, Gaithersburg, Maryland.

[23] De Ris, J., Wua, P.K., Heskestad, G., (2000) Radiation Fire Modeling, Proceedings of the Combustion Institute, 27(2): 2751-2759, http://dx.doi.org/10.1016/s0082-0784(00)80696-7

[24] Steinhaus, T., Welch, S., Carvel, R., Torero, J., (2007) Large-Scale Pool Fires, Thermal Science Journal, 11(3): Special on Fire, http://dx.doi.org/10.2298/TSCI0702101S

[25] McGrattan, K.B., Baum, H.R., Rehm, R.G., Hamins, A., Forney, G.P., "Fire Dynamics Simulator, Technical Reference Guide", Technical Report NISTIR 6467, 2000, National Institute of Standards and Technology, Gaithersburg, Maryland.

[26] McGrattan, K.B., Forney, G., "Fire Dynamics Simulator (Version 4), User's Guide”, NIST Special Publication 1019, 2006, National Institute of Standards and Technology, Gaithersburg, Maryland.

[27] Zukoski, E. E., Cetegen, B., Kubota, T., "Visible Structure of Buoyant Diffusion Flames" $20^{\text {th }}$ (International) Symposium on Combustion, The Combustion Institute, Pittsburgh, PA, 1984, 361366, http://dx.doi.org/10.1016/s0082-0784(85)80522-1

[28] McGrattan, K.B., Klein, B., Hostikka S., Floyd, J., "Fire Dynamics Simulator (Version 5), User's Guide", NIST Special Publication 1019-5, 2007, National Institute of Standards and Technology, Gaithersburg, Maryland. 